\title{
Avaliação das Razões Molares Cl/Nd e Al/Nd na Polimerização de 1,3-butadieno com o Sistema Catalítico Versatato de Neodímio/hidreto de Di-isobutilalumínio/cloreto de t-butila
}

\author{
Neusa Maria Tocchetto Pires, Bluma Guenther Soares \\ Instituto de Macromoléculas Professora Eloisa Mano, Universidade Federal do Rio de Janeiro \\ Fernanda Margarida Barbosa Coutinho ${ }^{\dagger}$, André Luiz Carneiro Simões, Marcos Antonio da Silva Costa \\ Instituto de Química, Universidade do Estado do Rio de Janeiro
}

\begin{abstract}
Resumo: O objetivo deste trabalho foi estudar sistemas catalíticos ternários constituídos por versatato de neodímio, cloreto de t-butila e hidreto de di-isobutil-alumínio para a polimerização de 1,4-cis de butadieno em hexano. Foram investigados os efeitos das razões molares $\mathrm{Cl} / \mathrm{Nd}$ e $\mathrm{Al} / \mathrm{Nd}$ sobre a reação de polimerização. Os polímeros foram caracterizados por cromatografia de exclusão por tamanho (SEC), espectroscopia na região do infravermelho (FTIR) e viscosimetria no estado fundido. A atividade catalítica, massa molar, distribuição de massa molar e viscosidade Mooney foram fortemente influenciados pela variação da razão molar $\mathrm{Cl} / \mathrm{Nd}$. Os maiores teores de unidades cis foram observados em razões molares $\mathrm{Cl} / \mathrm{Nd} \geq 3$. O valor máximo de atividade catalítica foi obtido em razões molares $\mathrm{Cl} / \mathrm{Nd}$ na faixa de 3 a 5. A microestrutura do polibutadieno foi significativamente influenciada pelo aumento da razão molar $\mathrm{Al} / \mathrm{Nd}$. Foi observado um valor máximo, $99 \%$ de unidades cis, na razão molar $\mathrm{Al} / \mathrm{Nd}=10$. Os dados de conversão versus tempo de reação mostraram que a velocidade de polimerização aumenta com a razão molar $\mathrm{Al} / \mathrm{Nd}$ alcançando um valor máximo na razão molar $\mathrm{Al} / \mathrm{Nd}=23$. As curvas de distribuição de massa molar evidenciaram um significativo processo de transferência de cadeia para os polímeros produzidos em razões $\mathrm{Al} / \mathrm{Nd}$ mais altas.
\end{abstract}

Palavras-chave: Catalisador Ziegler-Natta, neodímio, cloreto de t-butila, hidreto de diisobutilalumínio, polibutadieno.

\section{Evaluation of $\mathrm{Cl} / \mathrm{Nd}$ and $\mathrm{Al} / \mathrm{Nd}$ Molar Ratios in the Polymerization of 1,3-butadiene with the Catalyst System Comprising Neodymium Versatate/ di-isobutylaluminium hydride /t-butyl Chloride}

\begin{abstract}
This work studied ternary catalyst systems composed of neodymium versatate, t-butyl chloride and diisobutylaluminium hydride used in the cis- 1,4 polymerization of butadiene in hexane. The effect of $\mathrm{Cl} / \mathrm{Nd}$ and $\mathrm{Al} / \mathrm{Nd} \mathrm{molar}$ ratios on the polymerization was investigated. The polymers were characterized by size exclusion chromatography (SEC), Fourier transform infrared spectroscopy (FT-IR) and viscosimetry in melted-state. The catalytic activity, molecular weight, molecular weight distribution and Mooney viscosity were strongly influenced by the $\mathrm{Cl} / \mathrm{Nd} \mathrm{molar}$ ratio. The highest cis contents were observed at $\mathrm{Cl} / \mathrm{Nd}$ molar ratio $\geq 3$. The maximum of catalytic activity was obtained at $\mathrm{Cl} / \mathrm{Nd}$ molar ratios between 3 and 5 . The microstructure of polybutadiene was significantly influenced by the increase in the Al/Nd molar ratio. The maximum value, $99 \%$ of cis content, was observed for the Al/Nd molar ratio $=10$. The conversion data versus reaction time showed that the rate of polymerization increases with the Al/ $\mathrm{Nd}$ molar ratio reaching a maximum in $\mathrm{Al} / \mathrm{Nd}=23$. The molecular weight distribution curves showed a significant chain transfer process for polymers produced at higher $\mathrm{Al} / \mathrm{Nd}$ molar ratios.
\end{abstract}

Keywords: Ziegler-Natta catalyst, neodymium, t-butyl chloride, diisobutylaluminium hydride, polybutadiene.

\section{Introdução}

Dentre os sistemas catalíticos empregados comercialmente, os de neodímio são capazes de produzir polibutadieno com o teor de cis mais elevado e com o mais baixo teor de unidades vinílicas ${ }^{[1,2]}$. Tal característica contribui positivamente para as propriedades físicas do polímero, uma vez que as unidades vinílicas são pontos de imperfeição da cadeia polimérica e assim interferem no processo de cristalização ${ }^{[1]}$.
A macroestrutura tem importância significativa na processabilidade do polímero. Uma larga distribuição de massa molar bem como um alto grau de ramificações permite um melhor processamento do polímero, entretanto prejudicam propriedades físicas tais como resistência ao rasgo e à abrasão ${ }^{[3-5]}$. Assim, deve haver um balanceamento dessas características de modo a se ter uma boa processabilidade e boas propriedades físicas.

Autor para correspondência: Marcos A. S. Costa, Instituto de Química, Universidade do Estado do Rio de Janeiro - UERJ, Rua São Francisco Xavier, 524, Maracanã, CEP 20550-900, Rio de Janeiro, RJ, Brasil, e-mail: marcoscosta.iq.uerj@gmail.com 'In memoriam. A Professora Fernanda M. B. Coutinho foi orientadora da Tese de Doutorado que deu origem aos resultados apresentados neste artigo. 
Os sistemas à base de neodímio permitem uma extensiva e controlada variação dos parâmetros estruturais e consequentemente das propriedades dos compostos vulcanizados. A distribuição de massa molar pode variar entre os dois extremos, desde muito estreita até muito larga (Mw/Mn entre 2 e 20), assim como o grau de ramificações que pode variar entre os limites considerado muito baixo e alto $(3 \text { e } 20 \%)^{[6]}$.

Sistemas catalíticos à base de lantanídeos, estereoespecíficos em relação à inserção 1,4-cis na polimerização de dienos, precisam conter em sua estrutura um halogênio ou outro grupo eletronegativo, caso contrário constituirão sistemas catalíticos estereorreguladores para a inserção 1,4-trans ${ }^{[7,8]}$. A variação da concentração do composto clorado na composição do sistema catalítico (razão molar $\mathrm{Cl} / \mathrm{Nd}$ ) afeta significativamente a atividade do catalisador, a massa molar e a distribuição de massa molar do polímero ${ }^{[9,10]}$. O teor do composto clorado deve ser otimizado, independente do tipo de doador, pois baixas ou altas concentrações, diminuem ou inibem a atividade catalítica $^{[9-15]}$. Existe uma razão $\mathrm{Cl} / \mathrm{Ln}$ ótima, onde a atividade do sistema catalítico é máxima. Para baixos teores de cloreto, uma baixa concentração de espécies ativas será formada devido à cloração insuficiente do lantanídeo. Isso leva a baixas atividades catalíticas, altas massas molares e largas distribuições de massas molares. Largas distribuições de massas molares são verificadas porque o número de sítios ativos solúveis é pequeno em relação ao número de sítios insolúveis. Altos teores de cloreto provocam uma supercloração do lantanídeo, resultando em catalisadores heterogêneos formados pela aglomeração de $\mathrm{NdCl}_{3}$ insolúvel, levando novamente a baixas atividades catalíticas, a altas massas molares e largas distribuições de massa molar ${ }^{[13]}$.

O principal papel dos compostos alquil-alumínio nos catalisadores Ziegler-Natta convencionais é a redução do metal de transição, sua alquilação e complexação. Nos catalisadores à base de halogenetos trivalentes dos lantanídeos, o composto alquil-alumínio é, sem dúvida, um alquilante, mas falha como agente redutor. As propriedades de complexação desses compostos são responsáveis pela não formação de sítio único. O efeito da estrutura do composto alquil-alumínio e suas propriedades elétron-aceptoras, sobre a capacidade de remover o ligante orgânico da esfera de coordenação do lantanídeo, levam à formação de diferentes tipos de sítios $\operatorname{ativos}^{[16]}$.

Segundo Cabassi ${ }^{[17]}$ e Ricci ${ }^{[18]}$, a baixa estabilidade das ligações sigma $\mathrm{C}-\mathrm{Nd}$, é responsável, em parte, pela baixa eficiência dos catalisadores lantanídicos à base de neodímio. O tipo e concentração do composto organoalumínio também devem ser considerados. $\mathrm{O}$ fato de somente uma pequena fração de $\mathrm{NdCl}_{3}$ ser alquilada é um outro fator que contribui para a baixa eficiência. As altas razões $\mathrm{Al} / \mathrm{Nd}$, requeridas para a polimerização 1,4cis do butadieno, podem ser associadas à dificuldade de alquilação dos haletos lantanídicos pelos compostos alquilalumínio $^{[8]}$. Zavadovskayaa ${ }^{[19]}$, entretanto, demonstrou que para o sistema $\mathrm{NdCl}_{3} \cdot \mathrm{Et}_{2} \mathrm{OH} / \mathrm{TIBA}$, a reação de troca entre o composto de neodímio e o alquilalumínio é razoavelmente efetiva em razões $\mathrm{Al} / \mathrm{Nd}$ na faixa de 15 a 20 , a $20^{\circ} \mathrm{C}$. O rendimento da reação, estimado pelo aumento da concentração de $\mathrm{AlR}_{2} \mathrm{Cl}$, foi de $50 \%$ em 4 h. Isso sugere que a instabilidade dos compostos organolantanídicos formados podem ser a causa da baixa concentração de centros ativos nos sistemas lantanídicos baseados em neodímio. $\mathrm{O}$ aumento da velocidade de polimerização com o aumento da razão $\mathrm{Al} / \mathrm{Nd}$ é justificado por um aumento da concentração de espécies ativas alquiladas, e consequentemente, do número de centros ativos ${ }^{[20,21]}$.

Catalisadores lantanídicos para a polimerização 1,4-cis de butadieno são efetivos em razões molares $\mathrm{Al} / \mathrm{Nd}$ na faixa de 15 a 30 , ou superiores ${ }^{[8]}$. O teor de alquil-alumínio também interfere na microestrutura do polibutadieno, provocando um decréscimo no teor de unidades 1,4-cis com o aumento da razão $\mathrm{Al} / \mathrm{Nd}^{[15,22]}$. Contudo, o teor de unidades 1,4-cis não varia com a razão $\mathrm{Al} / \mathrm{Nd}$ quando a polimerização é realizada a baixas temperaturas $\left(-70^{\circ} \mathrm{C}\right)$, mas varia para temperaturas superiores a $0^{\circ} \mathrm{C}^{[23,24]}$. O aumento da concentração do composto organoalumínio provoca uma diminuição no teor de unidades 1,4-cis do polibutadieno, pois estabiliza o complexo alílico formado entre o composto de neodímio e o monômero. Isso aumenta o tempo de vida do complexo, e consequentemente favorece a isomerização para configuração mais favorecida estereoquimicamente, mas menos favorecida termodinamicamente ${ }^{[25]}$. Todos os sistemas reguladores cis são caracterizados por elevadas constantes de propagação da cadeia ${ }^{[8]}$.

$\mathrm{O}$ teor do composto alquil-alumínio influencia significativamente a massa molar e a distribuição de massa molar ${ }^{[26]}$. A massa molar diminui e a polidispersão aumenta com o aumento da razão $\mathrm{Al} / \mathrm{Nd}$. Assim, para que $\mathrm{o} \mathrm{AlEt}_{3}$ produza um polibutadieno com a mesma massa molar que a produzida por $\mathrm{Al}(\mathrm{i}-\mathrm{Bu})_{2} \mathrm{H}$, as razões $\mathrm{Al} / \mathrm{Nd}$ devem ser 60:1 ao invés do valor normal 25:1 ${ }^{[14]}$. Esse comportamento é justificado pela ocorrência de reações de transferência de cadeia para o composto alquilalumínio $^{[21]}$, que são acentuadas para os hidretos de alquil-alumínio.

O processo de transferência de cadeia mais importante com esses catalisadores é aquele que ocorre entre a cadeia em crescimento e o composto alquil-alumínio ${ }^{[7,21,26,27]}$. Há um consenso na literatura sobre a percentagem de neodímio realmente ativa nesses catalisadores, que seria de cerca de 6 a $8 \%$ do neodímio total presente ${ }^{[17,18,28-30]}$. Entretanto, o número de moléculas de polímero por mol de $\mathrm{Nd}$, pode ultrapassar a unidade, indicando a ocorrência significativa de processo de transferência de cadeia. $\mathrm{O}$ número de cadeias de polímero por mol de $\mathrm{Nd}$ aumenta com a conversão ${ }^{[21]}$ e com a concentração do composto alquil-alumínio, comprovando o processo de transferência de cadeia para esse composto. Os hidretos de alquil-alumínio são muito mais ativos como agentes de transferência de cadeia do que os compostos trialquilalumínio. Por essa razão os polímeros resultantes possuem as mais baixas massas molares e as mais largas polidispersões. Estudos mostram que a transferência de cadeia com os hidretos de alquil-alumínio envolve o deslocamento do íon hidreto do alumínio para o neodímio, ao invés dos radicais alquila ${ }^{[31]}$. A velocidade de propagação não é proporcional à concentração do DIBAH $^{[32]}$. O fato de os compostos alquil-alumínio de cadeia longa produzirem polímeros de massa molar 
somente mais altos do que os produzidos pelos hidretos de alquil-alumínio, não significa que eles transferem muito, pois quando sua concentração é aumentada a massa molar do polímero, praticamente não varia ${ }^{[16]}$. A reatividade e a tendência à formação de associações devem ser levadas em conta, pois somente a forma monomérica do composto alquil-alumínio é responsável pela transferência de cadeia ${ }^{[32]}$.

Apesar do número razoável de trabalhos publicados nesta área, a comparação dos dados é dificultada devido à diversidade de sistemas catalíticos e de detalhes experimentais ou a falta desses detalhes, empregadas pelos diferentes autores. O cloreto de t-butila, por exemplo, embora pouco citado na literatura como doador de cloro em substituição ao alquil-alumínio clorado é utilizado comercialmente em plantas industriais ${ }^{[1]}$. Além disso, para o sistema catalítico versatato de neodímio/ hidreto de di-isobutilalumínio/cloreto de t-butila o número de publicações é ainda mais restrito ${ }^{[1,3,5,10,20]}$. Assim, o objetivo deste trabalho foi estudar os efeitos das razões molares $\mathrm{Cl} / \mathrm{Nd}$ e $\mathrm{Al} / \mathrm{Nd}$ sobre a reação de polimerização de 1,4 cis de butadieno com sistemas catalíticos ternários constituídos por versatato de neodímio, cloreto de t-butila e hidreto de di-isobutil-alumínio.

\section{Experimental}

\section{Materiais}

Para a síntese dos catalisadores foram utilizados hidreto de di-isobutilalumínio, DIBAH (Akzo-Nobel), versatato de neodímio (Rhodia) e cloreto de t-butila (Sigma-Aldrich) em solução em hexano seco. Para a polimerização foram utilizados 1,3-butadieno, $n$-hexano (Petroflex Indústria e Comércio), purificado e seco em peneira molecular de $3 \AA$ (Angstron), nitrogênio super-seco, (White Martins). $\mathrm{O}$ antioxidante, fosfito de trinonilfenila (TNPP) e os terminadores, Irganox 1076 e 3,5-di-t-butil-4- hidroxitolueno (BHT) foram utilizados na forma de soluções em hexano a 10 e $50 \%$, respectivamente.

\section{Síntese do catalisador}

O catalisador padrão foi preparado seguindo as seguintes etapas: uma solução de alquilalumínio foi introduzida, por meio de seringa, em um frasco de $300 \mathrm{ml}$ vedado com septo de borracha. Em seguida, o frasco foi colocado em banho de água e gelo a $5^{\circ} \mathrm{C}$ e deixado por alguns minutos até que a temperatura atingisse o equilíbrio. Em seguida, uma solução de versatato de neodímio foi adicionada ao frasco, também por meio de seringa, e este foi agitado levemente para total mistura das duas soluções. Após 10 minutos, foi adicionado cloreto de t-butila. A solução obtida foi mantida a $10^{\circ} \mathrm{C}$ durante, pelo menos, 10 horas antes de ser utilizada na polimerização.

\section{Síntese do polímero}

A síntese do polímero foi realizada em planta piloto de aço inox, em atmosfera inerte (nitrogênio) equipada com 2 reatores Parr de 1 e 2 galões de capacidade. A reação de polimerização foi executada no reator de 2 galões, onde os componentes foram adicionados na seguinte ordem: solução hexânica a $35 \%$ em peso de butadieno (Blend B), parte do hexano, catalisador e o restante do hexano. O catalisador foi alimentado ao reator por intermédio de um cilindro de aço inox de $50 \mathrm{ml}$ de capacidade, acoplado ao reator. Esse cilindro foi carregado com o catalisador, sob fluxo de nitrogênio, por intermédio de seringa. $\mathrm{O}$ catalisador contido no cilindro de $50 \mathrm{ml}$ é então adicionado ao reator, carreado pelo restante do solvente, após a massa reacional (Blend B mais solvente) atingir a temperatura definida para o início da reação. Todos os componentes foram adicionados ao reator por diferença de pressão. As reações foram conduzidas isotermicamente e "adiabaticamente". As reações isotérmicas realizadas a $70^{\circ} \mathrm{C}$ foram controladas a esta temperatura pela admissão de uma mistura de vapor e água na camisa do reator. As reações chamadas "adiabáticas" tiveram sua temperatura inicial de $78^{\circ} \mathrm{C}$ controlada pelo mesmo sistema das reações isotérmicas. Após esta temperatura inicial ser alcançada, a camisa do reator era drenada e as reações eram conduzidas sem controle de temperatura até que o pico de temperatura, decorrente do calor de polimerização fosse atingido. A patir deste ponto, a temperatura da reação era novamente controlada, sendo mantida em $95^{\circ} \mathrm{C}$.

A polimerização foi acompanhada através da determinação do teor de sólidos durante todo o tempo estabelecido para a polimerização, e/ou após a reação ter atingido conversão total, ou ainda, após a estabilização da conversão. O cemento (polímero obtido pela reação de polimerização em solução) foi transferido para o segundo reator, de 1 galão de capacidade, inertizado, já contendo o terminador, solução de BHT em hexano, a 50\% em peso. A reação de terminação do polímero foi conduzida, sob agitação, a $60^{\circ} \mathrm{C}$, por pelo menos 20 minutos. Em seguida, o cemento foi estabilizado, utilizando-se uma solução de TNPP e Irganox 1076 em hexano, a 10\% em peso de TNPP, sendo utilizada uma razão TNPP/ Irganox 1076 igual a 1:2. Após o término das etapas de terminação e estabilização do polímero, o cemento foi descarregado para um recipiente para posterior coagulação. A coagulação foi realizada em um recipiente de aço inox, de 20 litros de capacidade, contendo água a $90^{\circ} \mathrm{C}$, mantida sob vigorosa agitação mecânica, por intermédio de um agitador pneumático com impelidor de alto cisalhamento. $\mathrm{O}$ cemento foi vertido lentamente no recipiente, sob intensa agitação.

Terminada a coagulação, os grumos de borracha foram recolhidos com uma peneira, picados manualmente, pois esse polímero apresenta uma tendência alta em se aglomerar formando uma massa única de polímero, e em seguida são colocados em uma bandeja de aço inox perfurada. A borracha coagulada foi levada à estufa para eliminação da água retida nos grumos durante o processo de coagulação. A secagem foi realizada, na própria bandeja de aço perfurada, em estufa com circulação forçada de ar, a $60-65^{\circ} \mathrm{C}$, durante pelo menos 12 horas.

\section{Caracterização dos polímeros}

A medida da massa molar ( $\mathrm{Mw}$ e $\mathrm{Mn}$ ) e distribuição da massa molar foi realizada por meio de cromatografia de exclusão por tamanho (SEC), em um sistema HPLC da Waters (Waters 600), equipado com detector de índice de refração; tetra-hidrofurano (THF) como solvente, com 
fluxo de $1 \mathrm{~mL} / \mathrm{min}$; análise realizada a $30^{\circ} \mathrm{C}$; utilizando um conjunto de 4 colunas de syragel de $5 \mu$ de diâmetro e porosidades equivalentes à faixa compreendida entre $5 \times 10^{2}$ a $10^{5} \AA$ e calibrado com padrões monodispersos de poliestireno (massas molares entre $10^{3}$ a $10^{6}$ ). As soluções poliméricas foram preparadas a $0,1 \%$ em massa em THF.

A viscosidade Mooney, ML(1+4), foi determinada segundo o método ASTM D $1646^{[14]}$, a $100^{\circ} \mathrm{C}$, em um viscosímetro modelo MV2000 da Alpha Technology. A medida da viscosidade de uma borracha no viscosímetro de cisalhamento a disco (viscosidade Mooney) é indicada pelo torque necessário para girar o rotor envolvido por uma amostra de borracha e fechado na cavidade de um molde, sob condições específicas. A amostra é condicionada à temperatura ambiente $\left(23 \pm 3^{\circ} \mathrm{C}\right)$ e posteriormente laminada para expelir o ar da amostra. Durante a análise a amostra é pré-aquecida a $100^{\circ} \mathrm{C}$, durante 1 minuto e a medição da viscosidade Mooney é feita em 4 minutos.

A microestrutura dos polibutadienos foi determinada em espectrômetro de infravermelho com transformada de Fourier (FTIR), Spectrum One - Perkin-Elmer, na forma de filmes vazados sobre células de $\mathrm{KBr}$, preparados a partir de soluções a $2 \%(\mathrm{p} / \mathrm{v})$ em clorofórmio. Os teores dos diferentes tipos de unidades repetitivas foram obtidos, segundo método descrito na literatura ${ }^{[33]}$, utilizando as absorbâncias a $725 \mathrm{~cm}^{-1}$ (1,4 cis), $910 \mathrm{~cm}^{-1}$ (1,2-vinila) e $965 \mathrm{~cm}^{-1}$ (1,4-trans).

Para fazer a integração de cada banda, foram traçadas linhas de base individuais, utilizando os seguintes valores para os limites de integração: de 542 a 895 cm-1 (cis1,4), de 898 a $925 \mathrm{~cm}^{-1}$ (1,2-vinila) e de 944 a $976 \mathrm{~cm}^{-1}$ (trans-1,4). O cálculo dos valores das absorbâncias foi feito utilizando o "Spectrum Software" v.3.01 da Perkin Elmer. O teor da cada tipo de unidade repetitiva foi obtido a partir das Equações 1 a 4, estabelecidas por Schröder ${ }^{[33]}$, considerando-se o total de insaturações igual a 100\%, uma vez que a espessura do filme polimérico não é conhecida.

$$
\begin{aligned}
& \% 1,4-\text { cis }=\left(A_{1} / 0,175\right) \times(100 / K) \\
& \% 1,4-\text { trans }=\left(A_{2} / 0,647\right) \times(100 / K) \\
& \% 1,2-\text { vinila }=\left(A_{3}\right) \times(100 / K) \\
& K=\left(A_{1} / 0,175+A_{2} / 0,647+A_{3}\right)
\end{aligned}
$$

Onde A1, A2 e A3 são respectivamente as absorbâncias das bandas correspondentes às configurações 1,4-cis, 1,4-trans e 1,2-vinila, localizadas em torno de $725 \mathrm{~cm}^{-1}$, $965 \mathrm{~cm}^{-1}$ e $910 \mathrm{~cm}^{-1}$. As constantes 0,175, 0,647 e 1,00 , são as absortividades, $\varepsilon$, das mesmas bandas, respectivamente, tiradas da literatura ${ }^{[33]}$.

\section{Resultados e Discussões}

A determinação da faixa em que a razão molar $\mathrm{Cl} / \mathrm{Nd}$ seria estudada, levou em conta dois aspectos: dados da literatura, onde o valor ótimo para esta razão se situa na faixa de 2 a 3, englobando os agentes doadores de cloro mais comuns; e nos resultados obtidos com a síntese de catalisadores preparados com razões altas e baixas. Dessa forma, decidiu-se estudar toda a faixa de variação desde a formação de um catalisador de baixa atividade (razões molares $\mathrm{Cl}$;Nd baixas) até a formação de catalisadores heterogêneos (razão molar $\mathrm{Cl} / \mathrm{Nd}$ alta). A faixa escolhida para essa razão foi de 1 a 6 . A variação da concentração do composto clorado, na composição do sistema catalítico (razão molar $\mathrm{Cl} / \mathrm{Nd}$ ), afetou significativamente a atividade do catalisador, a massa molar, a distribuição da massa molar e a viscosidade Mooney do polímero, enquanto a microestrutura foi só ligeiramente modificada.

A Figura 1 mostra a influência exercida pela concentração do composto doador de cloro sobre a atividade catalítica. A Figura 1a apresenta esta influência por meio da evolução da conversão do monômero com o tempo de reação.

Pode-se observar claramente a existência de uma faixa ótima de concentração do composto doador de cloro, compreendida entre as razões molares 2,94:1 e 4,85:1, aproximadamente $3: 1$ e 5:1. Razões mais baixas ou mais altas retardam a polimerização. A Figura $1 \mathrm{~b}$ representa outra maneira de mostrar tal influência, a partir da análise das curvas de atividade ao longo da reação de polimerização, para cada concentração do composto clorado utilizado no preparo do catalisador. Esta queda de atividade apresentada nos extremos opostos da razão molar $\mathrm{Cl} / \mathrm{Nd}$, pode ser justificada, para baixas concentrações de cloreto, pela presença de um menor número de sítios ativos ou pela presença de sítios menos ativos. Os dados de massa molar obtidos, Tabela 1, reforçam a segunda teoria, presença de sítios

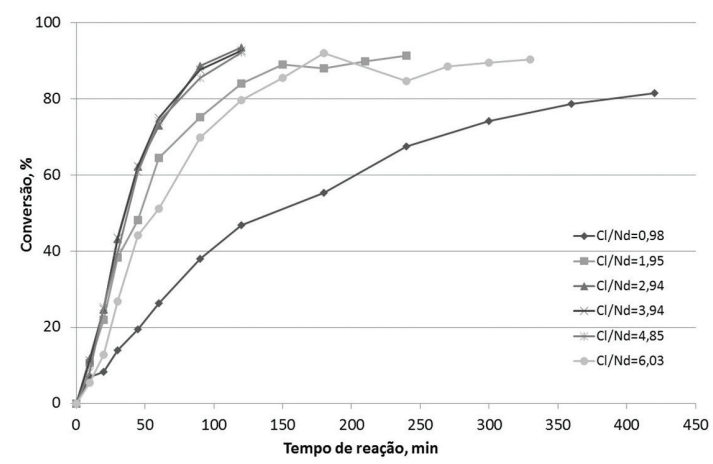

(a)

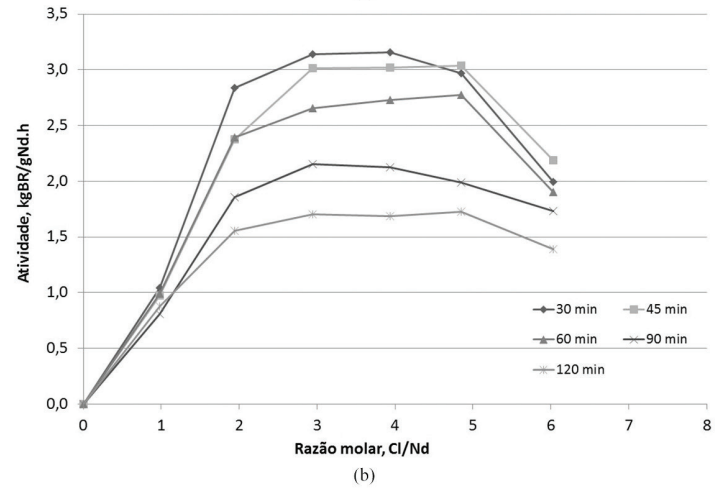

Figura 1. Influência da razão molar $\mathrm{Cl} / \mathrm{Nd}$ sobre reação de polimerização: atividade catalítica (a) e conversão (b). $[\mathrm{Nd}]=0,20 \mathrm{mmol} / 100 \mathrm{~g} \mathrm{Bd}$; $[\mathrm{Bd}]=6,5 \%$ em peso; razão molar $\mathrm{Al} / \mathrm{Nd}=15 ; \mathrm{T}=70^{\circ} \mathrm{C}$. 
menos ativos, pois se o número de sítios fosse menor, as massas molares resultantes para os polímeros sintetizados com baixas razões molares $\mathrm{Cl} / \mathrm{Nd}$, seriam as maiores, uma vez que as conversões alcançadas estão todas muito próximas. Para altas concentrações de cloreto, a queda de atividade pode ser justificada pela coexistência de sítios solúveis e insolúveis, com possível predominância dos últimos. A predominância dos sítios insolúveis pode ser atribuída à ocorrência de uma supercloração do composto de neodímio, causada pelo excesso do agente de cloração, diminuindo a solubilidade do sítio, e consequentemente, sua atividade. Na etapa em que os radicais orgânicos seriam substituídos pelo cloreto $^{[34]}$, é que deve ocorrer a supercloração.

A faixa de valores da razão $\mathrm{Cl} / \mathrm{Nd}$ compreendida entre 3:1 e 5:1, onde a atividade catalítica é máxima, encontrada nos experimentos deste trabalho, diferem dos valores citados na literatura, 2,0 a 2,5 ${ }^{[13]}$. Este fato não surpreende, pois as condições experimentais dos trabalhos existentes na literatura diferem entre si e diferem das utilizadas neste trabalho. Além disso, não estão descritas detalhadamente.

O comportamento da massa molar, distribuição de massa molar e da viscosidade Mooney é mostrado na Tabela 1 .

Os dados obtidos para a massa molar, distribuição de massa molar e para a viscosidade Mooney, foram analisados em conversões semelhantes, exceto para a concentração mais baixa, $\mathrm{Cl} / \mathrm{Nd}=0,98$, aonde a diferença de conversão chega a $12 \%$, em relação aos demais experimentos. Estes valores mostram uma tendência para valores mais altos à medida que a razão molar $\mathrm{Cl} / \mathrm{Nd}$ é aumentada.

Este comportamento pode ser atribuído ao aumento do número de sítios ativos insolúveis com o aumento da razão $\mathrm{Cl} / \mathrm{Nd}$, devido à supercloração do composto de neodímio. Por outro lado, observa-se na Tabela 1 , que a polidispersão não foi significativamente alterada. Como todas as reações foram levadas até altas conversões, uma explicação poderia ser devido a existência de dois tipos de sítios: insolúveis (alta velocidade de polimerização, polímeros de altas massas molares e vida curta) e solúveis (velocidade de polimerização mais lenta, prosseguindo de maneira "quase viva", polímeros de massas molares mais baixas e polidispersões mais estreitas em 100\% de conversão) $)^{[35,36]}$. Wilson \& Jenkins ${ }^{[13]}$ relatam que, para baixas concentrações de cloreto, a distribuição de massa molar se alarga devido à existência de um número maior de sítios ativos insolúveis em relação aos sítios solúveis. Esta afirmação, entretanto, não está bem suportada, pois se a concentração de cloreto é pequena, abaixo da estequiométrica, o composto de neodímio não poderá atingir um grau de cloração suficiente para torná-lo insolúvel. O que pode ocasionar um alargamento da distribuição de massa molar é a "heterogeneidade" dos sítios formados, ou seja, a diversidade de tipos de sítios ativos, levando-se em conta que o composto de neodímio pode ser clorado por um número diferente de cloretos, e que cada um destes sítios dá origem a polímeros com distintas características. Seguindo este raciocínio, à medida que a razão $\mathrm{Cl} / \mathrm{Nd}$ vai sendo aumentada o grau de cloração torna-se mais uniforme e a distribuição de massas molares tende a se estreitar. Esta tendência, entretanto, não ficou nítida nos dados obtidos neste trabalho. Esta hipótese pode ser suportada pela publicação de $\mathrm{Kwag}^{[34]}$ onde o composto de neodímio é suposto existir como uma estrutura oligomérica ou polimérica, com diferentes ligantes polares, tais como a água, hidróxidos e carboxilatos.

O fato é que a análise da distribuição de massa molar obtida por GPC para o polibutadieno alto-cis, sintetizado a partir do sistema catalítico ternário baseado em versatato de neodímio, hidreto de diisobutil-alumínio e cloreto de t-butila, apresenta uma "cauda" muito longa na região de baixas massas molares. Isso torna difícil a repetibilidade do critério de escolha dos limites de integração da curva produzida durante a análise. Adicionalmente, polímeros de massa molar muito alta, além de necessitarem de um tempo maior de dissolução (o tempo de dissolução é padrão, no método utilizado neste trabalho), podem eventualmente ficar retidos no filtro, na etapa de filtração das soluções poliméricas, antes da injeção no cromatógrafo de permeação em gel. Isso alteraria o resultado final da análise. Observou-se ainda, que para este polímero a concentração em que a solução polimérica é preparada para ser injetada no GPC, interfere nos resultados. Neste trabalho foi utilizada uma única concentração para a solução polimérica, independente do valor da massa molar do polímero, avaliado, preliminarmente, através da medida de viscosidade Mooney. Conforme explicado na metodologia, o valor de concentração utilizado foi de $0,1 \%$ em peso em THF. Assim a variação na polidispersão pode não ser grande o suficiente para superar as dificuldades devido aos problemas inerentes à análise.

A avaliação da viscosidade Mooney, análise feita no polímero sólido, indica uma variação significativa entre os valores obtidos nos extremos da faixa de razão molar $\mathrm{Cl} / \mathrm{Nd}$ estudada, e entre estes valores e os demais. Entretanto, a variação de viscosidade Mooney registrada

Tabela 1. Influência da razão molar $\mathrm{Cl} / \mathrm{Nd}$ na massa molar e distribuição da massa molar.

\begin{tabular}{|c|c|c|c|c|c|}
\hline Razão molar Cl/Nd & Conversão (\%) & $\operatorname{Mnx} 10^{-3}(\mathrm{~g} / \mathrm{mol})$ & $\operatorname{Mwx10}{ }^{-3}(\mathrm{~g} / \mathrm{mol})$ & Mw/Mn & V. Mooney $\left(\mathrm{ML}_{4}\right)$ \\
\hline 0,98 & 81,6 & 103 & 398 & 3,9 & 31,6 \\
\hline 1,95 & 91,3 & 124 & 468 & 3,8 & 42,2 \\
\hline 2,94 & 93,6 & 132 & 542 & 4,1 & 43,0 \\
\hline 3,94 & 92,8 & 125 & 517 & 4,1 & 43,0 \\
\hline 4,85 & 92,2 & 135 & 529 & 3,9 & 42,9 \\
\hline 6,03 & 90,3 & 149 & 551 & 3,7 & 47,5 \\
\hline
\end{tabular}

$[\mathrm{Nd}]=0,20 \mathrm{mmol} / 100 \mathrm{gBd} ;[\mathrm{Bd}]=6,5 \%$ em peso; $\operatorname{razão~molar~} \mathrm{Al} / \mathrm{Nd}=15 ; \mathrm{T}=70^{\circ} \mathrm{C}$. 
para os polímeros obtidos com razões molares $\mathrm{Cl} / \mathrm{Nd}$ na faixa de 2 a 5, se manteve praticamente constante.

A análise dos conjuntos de resultados obtidos para massa molar, distribuição de massa molar e viscosidade Mooney, na faixa de valores de concentração estudada neste trabalho, para o agente de cloração, permite formular a seguinte hipótese: a presença do doador de cloro influencia significativamente a atividade da reação. Quando este agente está presente em baixas ou altas concentrações, o número de sítios ativos formados parece não ser muito diferente, o que é significativamente diferente é a atividade dos sítios formados em baixas concentrações de cloreto com relação aqueles produzidos em altas concentrações.

Esta hipótese explicaria a diferença significativa encontrada na conversão e na atividade catalítica ao longo da reação para as duas concentrações mais baixas do agente de cloração, sem a variação concomitante da massa molar e da viscosidade Mooney do polímero final. Os valores destas propriedades foram menores para a concentração mais baixa do agente de cloração, também devido à mais baixa conversão alcançada em relação às demais reações.

A microestrutura dos polímeros obtidos, Figura 2, não foi significativamente alterada quando se analisa os resultados em uma escala de valores de 0 a $100 \%$ para o teor das diferentes unidades repetitivas. Entretanto, quando se amplia a faixa de percentagem dessas unidades (95 a 99\%) verifica-se, uma tendência bastante interessante. $\mathrm{O}$ teor de unidades cis cresce visivelmente até valores de razão molar $\mathrm{Cl} / \mathrm{Nd}$ próximo de 3 , a partir daí permanece constante. Esse comportamento está de acordo com os dados de atividade catalítica.

Até razão molar $\mathrm{Cl} / \mathrm{Nd}=3$, os sítios catalíticos têm sua atividade aumentada em função da sua cloração mais extensa, ocasionada pelo aumento da concentração de cloreto, consequentemente a velocidade da polimerização também vai aumentando. Quanto mais rápida for a velocidade de reação, menor a probabilidade de ocorrer a isomerização da configuração $c$ is para a configuração trans (termodinamicamente mais estável) do último mero inserido na cadeia polimérica. Em valores mais altos de concentração de cloreto, a atividade catalítica cai, mas não interfere na microestrutura.

\section{Avaliação da razão molar $\mathrm{Al} / \mathrm{Nd}$}

Para se determinar a faixa da razão molar $\mathrm{Al} / \mathrm{Nd}$ foram estabelecidos dois critérios: achar a razão molar mínima, abaixo da qual a reação não se verificava, e encontrar a razão molar máxima, acima da qual a viscosidade Mooney resultante era tão baixa que o polímero já não teria mais as características desejadas. Após um pequeno número de reações com valores extremos dessa variável, chegou-se à conclusão que a razão molar $\mathrm{Al} / \mathrm{Nd} \leq 5$, era impraticável, pois as reações eram de baixa repetibilidade. Qualquer impureza mudava as características do sistema catalítico, e este era de baixa atividade. Valores acima da razão molar $\mathrm{Al} / \mathrm{Nd}>50$, levavam à produção de polímeros com massa molar muito baixa, fora da faixa considerada comercial. Dessa forma, decidiu-se estudar o comportamento do sistema catalítico variando-se a razão

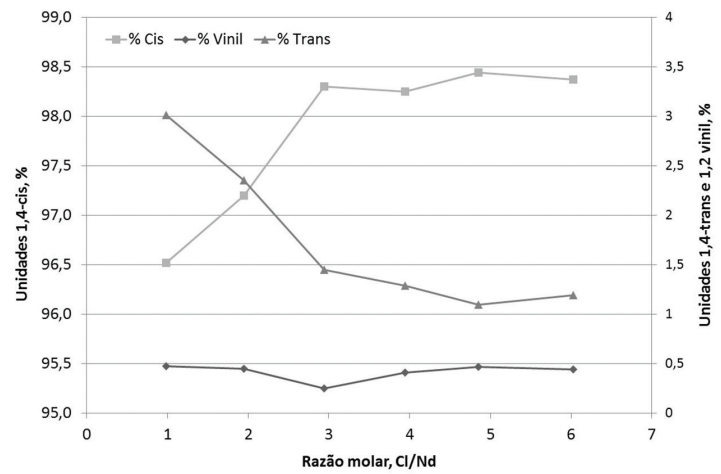

Figura 2. Influência da razão molar $\mathrm{Cl} / \mathrm{Nd}$ sobre a microestrutura $[\mathrm{Nd}]=0,20 \mathrm{mmol} / 100 \mathrm{~g} \mathrm{Bd} ;[\mathrm{Bd}]=6,5 \%$ em peso; razão molar $\mathrm{Al} / \mathrm{Nd}=15 ; \mathrm{T}=70^{\circ} \mathrm{C}$.

molar Al/Nd na faixa compreendida entre 10 e 50. Neste estudo foram utilizadas razões molares $\mathrm{Al} / \mathrm{Nd}$ variando de 10 a 50. O efeito desta variação foi avaliado a partir de dois conjuntos diferentes de reações. A influência sobre a conversão, a atividade catalítica, a microestrutura, a distribuição de massa molar e a viscosidade Mooney, foi estudada a partir dos resultados do primeiro conjunto de reações. A partir do segundo conjunto de reações, foram avaliadas as correlações existentes entre a razão molar $\mathrm{Al} / \mathrm{Nd}$ e a massa molar, a distribuição de massa molar e novamente a viscosidade Mooney, utilizando neste segundo estudo diferentes concentrações de neodímio na reação.

Na Figura 3a os dados de conversão da reação foram plotados contra o tempo de reação, para cada razão molar $\mathrm{Al} / \mathrm{Nd}$ estudada. Os resultados obtidos mostram que a velocidade de polimerização aumenta com a razão molar $\mathrm{Al} / \mathrm{Nd}$, passa por um máximo, em $\mathrm{Al} / \mathrm{Nd}=23$, e decresce ligeiramente com aumentos adicionais desta razão. Também pode ser observado a influência da razão molar $\mathrm{Al} / \mathrm{Nd}$ sobre a atividade catalítica, em diferentes tempos da reação (Figura 3b). Ficou evidenciado o ponto de atividade catalítica máxima, para a razão $\mathrm{Al} / \mathrm{Nd}=23$, para qualquer tempo de reação, e mostra o decréscimo do rendimento de polímero ao longo da reação.

Conforme descrito na literatura ${ }^{[21]}$, o aumento da velocidade de polimerização com o aumento da razão $\mathrm{Al} / \mathrm{Nd}$ é justificado por um aumento da concentração de espécies ativas alquiladas, e consequentemente, do número de centros ativos formados. Como o hidreto de diisobutil-alumínio apresenta a tendência de formar espécies associadas intermolecularmente, trímeros, à medida que a concentração do alquil-alumínio aumenta, o processo de associação é favorecido, diminuindo seu poder de alquilação, e, com isso, a concentração de centros ativos. Este comportamento peculiar do alquilalumínio pode explicar o decréscimo da velocidade de reação com o aumento da razão Al/Nd após o valor considerado ótimo.

Os dados relatados na literatura descrevendo as correlações existentes entre o rendimento da polimerização e o valor da relação $\mathrm{Al} / \mathrm{Nd}$, à semelhança do que foi observado no estudo anterior, diferem entre $\mathrm{si}^{[1]}$. Para que a comparação pudesse ser efetuada, as condições 


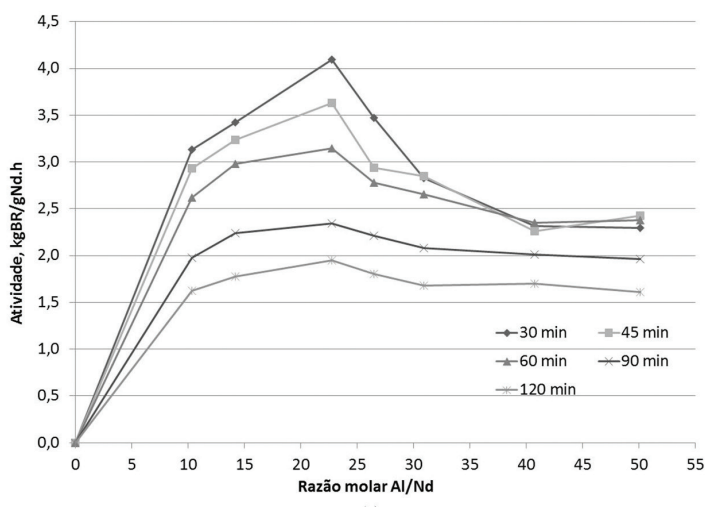

(a)

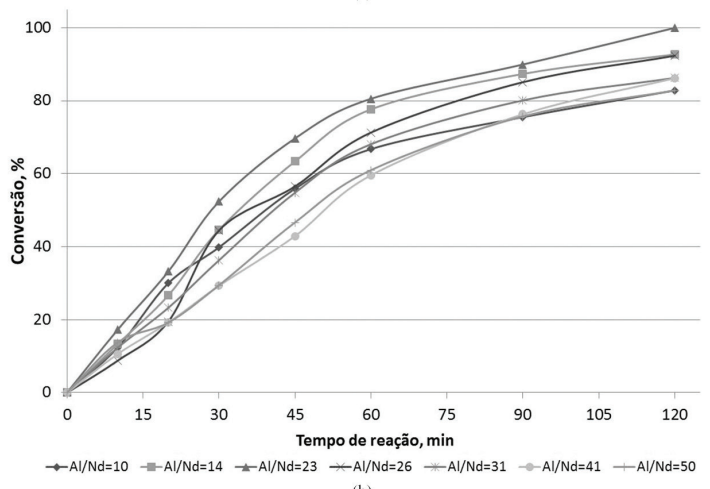

(b)

Figura 3. Influência da razão molar $\mathrm{Al} / \mathrm{Nd}$ sobre a reação de polimerização: conversão (a) e atividade catalítica (b). $[\mathrm{Nd}]=0,20 \mathrm{mmol} / 100 \mathrm{~g} \mathrm{Bd} ;[\mathrm{Bd}]=6,5 \%$ em peso; razão molar $\mathrm{Cl} / \mathrm{Nd}=2,9$; Temperatura da reação $=70^{\circ} \mathrm{C}$; tempo de reação= 120 minutos.

reacionais, principalmente a temperatura de reação, bem como a concentração e tipo de alquil-alumínio deveriam ser equivalentes, pois caso contrário cada sistema terá um comportamento diferenciado. A tendência do rendimento da reação aumentar ${ }^{[37,38]}$, estabilizar ${ }^{[18]}$ ou decrescer ${ }^{[37]} \mathrm{com}$ o aumento da razão $\mathrm{Al} / \mathrm{Nd}$, todas descritas na literatura, vai depender fortemente da estrutura do alquil-alumínio, se ele se associa ou não em solução, e da temperatura em que este processo deixa de ser significativo. Fica claro, que é praticamente impossível fazer generalizações de comportamento para esses sistemas.

A Figura 4 mostra que a microestrutura do polibutadieno obtido foi significativamente influenciada pelo aumento da razão molar $\mathrm{Al} / \mathrm{Nd}$, passando de um valor próximo a $99 \%$ de unidades 1,4-cis, em razão mol ar $\mathrm{Al} / \mathrm{Nd}=10$, para um valor próximo a $93 \%$ de unidades 1,4-cis, para razão molar Al/Nd=50. Observe-se que toda a variação apresentada pelo teor de unidades 1,4-cis é compensada por igual variação do teor de unidades 1,4-trans, mantendo-se praticamente constante o teor de unidades 1,2 vinila. A variação dos teores de unidades cis e trans apresentada neste estudo foi considerada importante, apesar da faixa de variação não ser muito grande, 93 a $99 \%$, pois as propriedades do polibutadieno mudam significativamente a partir de $80 \%$ de unidades 1,4-cis. Além disso, quanto mais próximo de $100 \%$, qualquer contaminação por uma quantidade tão

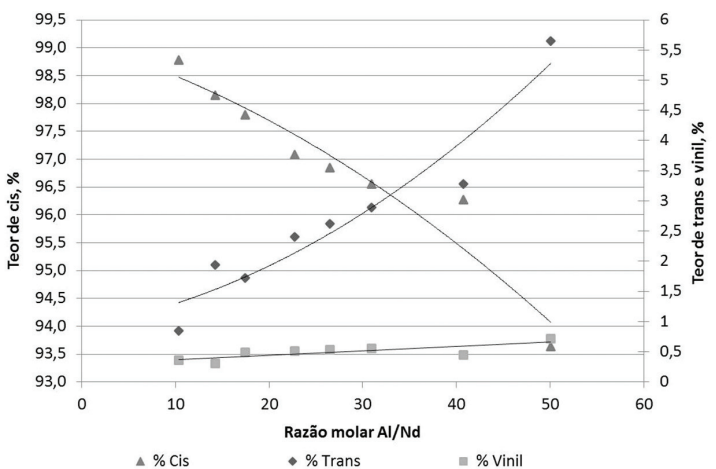

Figura 4. Influência da razão molar $\mathrm{Al} / \mathrm{Nd}$ sobre a microestrutura do polibutadieno. $[\mathrm{Nd}]=0,20 \mathrm{mmol} / 100 \mathrm{gBd} ;[\mathrm{Bd}]=6,5 \% \mathrm{em}$ peso; razão molar $\mathrm{Cl} / \mathrm{Nd}=2,9$; Temperatura da reação $=70^{\circ} \mathrm{C}$; tempo de reação $=120$ minutos.

pequena quanto $0,5 \%$ de outra configuração, 1,4-trans ou 1,2-vinila, diminui a capacidade de cristalização sob tensão, característica dos polibutadienos com alto teor de unidades cis, interferindo negativamente nas propriedades mecânicas do polímero final. O aumento do teor de unidades trans, com o aumento da razão molar $\mathrm{Al} / \mathrm{Nd}$, se deve à maior estabilização do complexo alílico formado entre o composto de neodímio e o monômero. Isso aumenta o tempo de vida do complexo, permitindo que ocorra a isomerização da forma cis para a forma trans, configuração menos favorecida estereoquimicamente, mas mais favorecida termodinamicamente.

A extensão da ação do hidreto de diisobutil-alumínio, como agente de transferência de cadeia foi estudada a partir dos dados de viscosidade Mooney e massa molar obtidas, Figuras 5 e 6, respectivamente. Observa-se claramente na Figura 6, o decréscimo da viscosidade Mooney à medida que o teor de alquil-alumínio é aumentado. Conforme descrito na literatura, este é o processo de transferência de cadeia mais importante para os sistemas com catalisadores à base de neodímio ${ }^{[7,26,27]}$, e, é um processo bastante intenso para o hidreto de diisobutil-alumínio $^{[21]}$. Para as condições estudadas neste conjunto de reações, a influência de um aumento de concentração do agente de transferência de cadeia é bastante acentuada até razão molar $\mathrm{Al} / \mathrm{Nd}=23$, de crescendo, só ligeiramente, para razões molares mais altas. A viscosidade Mooney dos polibutadienos obtidos com razões Al/Nd maiores do que 31, não foi possível ser medida, face ao seu valor extremamente baixo. Valores de viscosidade Mooney abaixo de 12 ML 4 tornam-se praticamente impossíveis de serem medidos.

As curvas de distribuição de massa molar evidenciam, também, um significativo processo de transferência de cadeia para os polímeros produzidos em razões $\mathrm{Al} / \mathrm{Nd}$ mais altas. O deslocamento dessas curvas para a região de massas molares mais baixas permitiu a definição de um pico de alta massa molar, provavelmente já existente, conferindo um aspecto bimodal às mesmas.

A Figura 7 refere-se, respectivamente, às curvas de eluição (a) e distribuição de massas molares (b). Optou-se por colocar, também, as curvas de eluição para melhor visualizar a bimodalidade ocorrida em razões $\mathrm{Al} / \mathrm{Nd}$ 


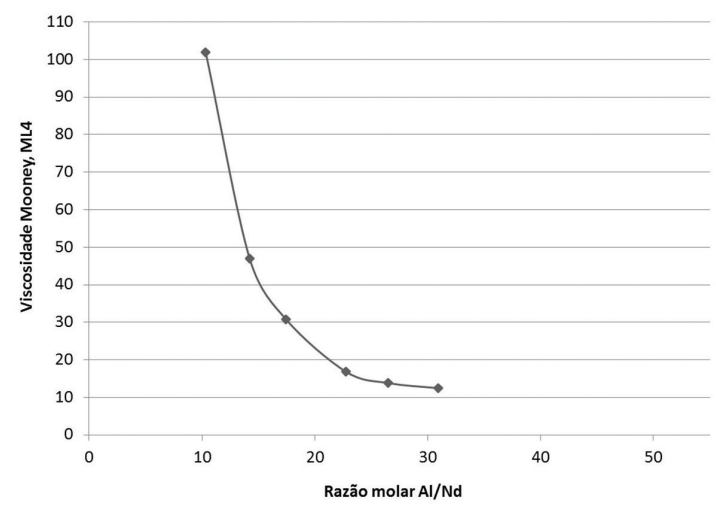

Figura 5. Influência da razão molar $\mathrm{Al} / \mathrm{Nd}$ sobre a viscosidade Mooney do polibutadieno. $[\mathrm{Nd}]=0,20 \mathrm{mmol} / 100 \mathrm{gBd}$; $[\mathrm{Bd}]=6,5 \%$ em peso; razão molar $\mathrm{Cl} / \mathrm{Nd}=2,9 ;$ Temperatura da reação $=70^{\circ} \mathrm{C}$; tempo de reação $=120$ minutos.

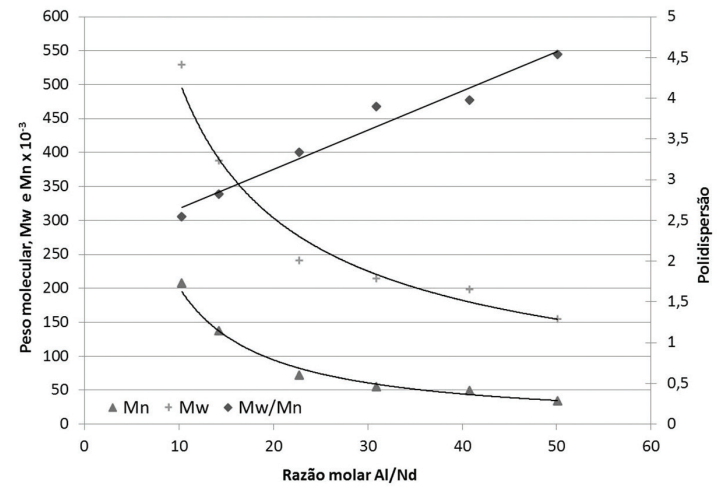

Figura 6. Influência da razão molar $\mathrm{Al} / \mathrm{Nd}$ sobre a massa molar e sobre a polidispersão do polibutadieno. $[\mathrm{Bd}]=12,5 \%$ em peso; razão molar $\mathrm{Cl} / \mathrm{Nd}=3,1$; temperatura da reação $=95^{\circ} \mathrm{C}$; tempo de reação= 120 minutos; "reação adiabática".

mais altas. Observa-se na curva de eluição, que a linha base não tem a mesma altura, antes e após a saída dos picos, provavelmente devido à presença de contaminantes polares na amostra. Isso faz com que o traçado da linha de distribuição fique com este aspecto de "curva inacabada" prejudicando um pouco a visualização da bimodalidade das curvas, claramente observada nas curvas de eluição.

As curvas de distribuição de massa molar resultantes da variação da razão $\mathrm{Al} / \mathrm{Nd}$ em uma faixa tão larga quanto 10 a 50, Figura 7, revelaram a existência de um tipo de sítio ativo responsável por altas massas molares, que em razões $\mathrm{Al} / \mathrm{Nd}$ normais passa desapercebido, pois o pico de alta massa fica "escondido" pela larga distribuição de massas molares. Foi verificado, que a partir de razão $\mathrm{Al} / \mathrm{Nd}=23$, a curva já está tão deslocada em direção a valores de massa molar baixa, que deixa à vista o pico de alta massa molar, resultando em curvas de distribuição de massas molares bimodais.

Wilson $^{[36]}$ fez referência a esse tipo de sítio, que gera polímero de alta massa molar e sugeriu que eram espécies ativas que ocorriam na superfície das partículas insolúveis, que poderiam não ser visíveis a olho nu. Essas espécies possuiriam elevada velocidade de polimerização, levando a altas massas molares em curto
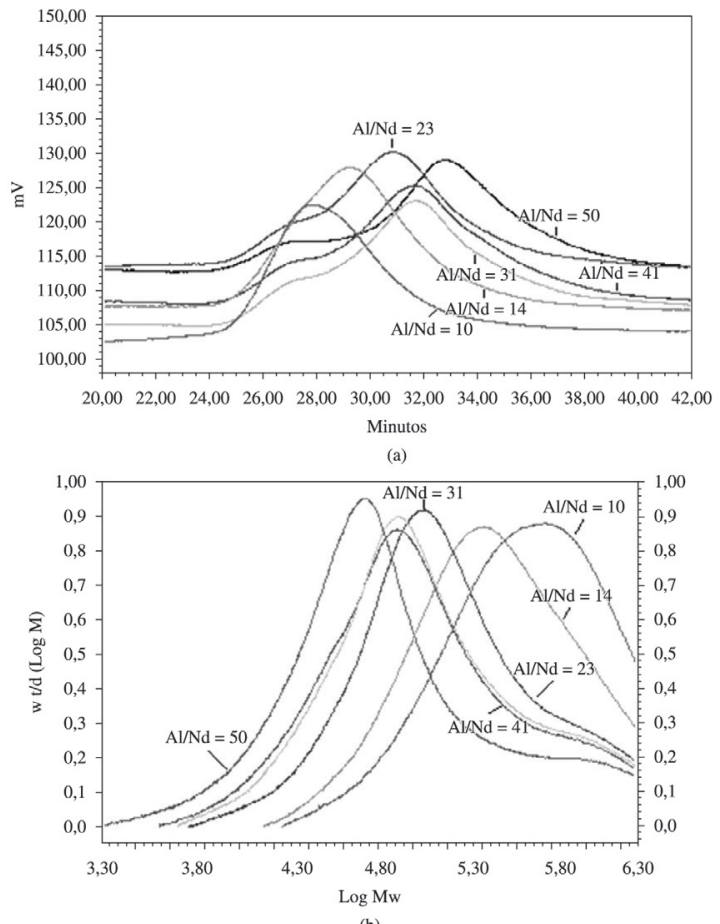

(b)

Figura 7. Influência da razão molar $\mathrm{Al} / \mathrm{Nd}$ sobre a distribuição de massa molar do polibutadieno. (a) Curva de eluição; (b) Curva de distribuição de massa molar. $[\mathrm{Nd}]=0,20 \mathrm{mmol} / 100 \mathrm{gBd}$; $[\mathrm{Bd}]=6,5 \% \mathrm{em}$ peso; razão molar $\mathrm{Cl} / \mathrm{Nd}=2,9$; temperatura da reação $=70^{\circ} \mathrm{C}$; tempo de reação $=120$ minutos.

espaço de tempo. Entretanto, seriam de vida curta, pois à medida que a cadeia crescesse, o acesso do monômero ao sítio iria se tornando difícil e a polimerização ficaria mais lenta. Os sítios se tornariam inoperantes, pois não haveria mais acesso para o monômero.

Os dados obtidos neste trabalho corroboram essa teoria, e enfatiza a elevada velocidade de polimerização desses sítios, que dificulta ao alquil-alumínio participar do processo de transferência para estas cadeias, processo este ainda mais inibido devido ao difícil acesso ao sítio pelo alquil-alumínio, tal como ocorre com o monômero.

O deslocamento das curvas de distribuição de massa molar, resultante do aumento da concentração de alquilalumínio no sistema catalítico, poderia ser atribuído a dois fatores: o aumento do número de sítios ativos, decorrente de um processo de alquilação mais intenso; e o aumento da intensidade do processo de transferência de cadeia. Ambos os fatores levariam ao decréscimo da massa molar. Entretanto, como o aumento da razão $\mathrm{Al} / \mathrm{Nd}$ favorece a associação do alquil-alumínio, com consequente perda de atividade catalítica, conforme discutido anteriormente, acredita-se que somente o processo de transferência de cadeia para o alquil-alumínio seja o fator responsável pelo comportamento observado. Ao que parece o processo de transferência seria mais favorecido do que o processo de alquilação, com o aumento da concentração de alquil-alumínio. Assim, as moléculas de alquilalumínio, ainda não associadas em estruturas triméricas, estariam envolvidas, prioritariamente, como processo de transferência de cadeia. 
Tabela 2. Influência da razão molar Al/Nd sobre a massa molar, distribuição da massa molar e viscosidade Mooney.

\begin{tabular}{|c|c|c|c|c|c|}
\hline [Nd] & $\mathbf{A l} / \mathbf{N d}$ & Conversão (\%) & $\operatorname{Mnx10} 0^{-3}(\mathrm{~g} / \mathrm{mol})$ & $\operatorname{Mwx10}^{-3}(\mathrm{~g} / \mathrm{mol})$ & Mw/Mn \\
\hline \multirow{4}{*}{0,16} & 10,0 & 77,9 & 153 & 633 & 4,1 \\
\hline & 16,5 & 91,2 & 156 & 520 & 3,3 \\
\hline & 20,6 & 86,0 & 125 & 440 & 3,5 \\
\hline & 24,4 & 89,3 & 93 & 439 & 4,7 \\
\hline \multirow{4}{*}{0,21} & 10,0 & 87,5 & 130 & 518 & 4,0 \\
\hline & 12,2 & 96,3 & 128 & 491 & 3,8 \\
\hline & 14,3 & 94,8 & 120 & 433 & 3,6 \\
\hline & 18,5 & 99,6 & 104 & 392 & 3,8 \\
\hline
\end{tabular}

$[\mathrm{Nd}] \mathrm{em} \mathrm{mmol} / 100 \mathrm{~g} \mathrm{Bd} ; \mathrm{Al} / \mathrm{Nd}=$ razão molar; $[\mathrm{Bd}]=12,5 \%$ em peso; razão molar $\mathrm{Cl} / \mathrm{Nd}=3,1 ;$ Temperatura $=95^{\circ} \mathrm{C}$; tempo de reação= 120 minutos; "reação adiabática".

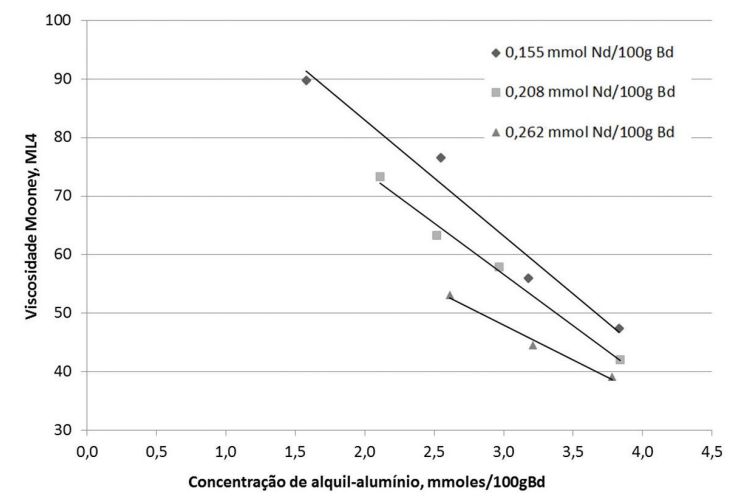

Figura 8. Influência da concentração total de alquilalumínio no sistema reacional, sobre a viscosidade Mooney do polibutadieno em diferentes concentrações de neodímio. $[\mathrm{Bd}]=12,5 \% \mathrm{em}$ peso; razão molar $\mathrm{Cl} / \mathrm{Nd}=3,1$; Temperatura $=95^{\circ} \mathrm{C}$; tempo de reação= 120 minutos; "reação adiabática".

É nítida a mudança de comportamento do sistema quando se ultrapassa a concentração de alquil-alumínio considerada ótima pela análise dos dados de atividade catalítica obtidos, $\mathrm{Al} / \mathrm{Nd}=23$. A viscosidade Mooney, praticamente, se estabiliza, em parte devido à dificuldade de realização da medida, conforme já discutido. A massa molar, entretanto continua a decrescer, a polidispersão continua a aumentar (Figura 6) e as curvas de distribuição de massa molar passam de monomodais para bimodais (Figura 7), confirmando a existência de sítios múltiplos.

Um segundo conjunto de reações foi realizado, em condições reacionais diferentes daquelas utilizadas anteriormente, e a massa molar, a distribuição de massa molar e a viscosidade Mooney dos polibutadienos obtidos foram avaliados. A síntese do polibutadieno, neste segundo conjunto de reações, foi efetuada utilizando-se uma concentração maior de monômero. Diferentes concentrações de neodímio foram utilizadas nas reações, e para cada concentração de neodímio, quatro diferentes razões molares $\mathrm{Al} / \mathrm{Nd}$ foram usadas. As condições utilizadas e os valores de massa molar e distribuição de massa molar estão listados na Tabela 2.

$\mathrm{O}$ efeito do aumento da razão molar $\mathrm{Al} / \mathrm{Nd}$ sobre a massa molar e viscosidade Mooney é tão mais acentuado quanto menor for a concentração de neodímio na reação, pois as massas molares antes da ocorrência da transferência de cadeia são mais elevadas e o impacto de uma transferência de cadeia é alto.

Este efeito torna-se nítido, quando os dados de viscosidade Mooney são correlacionados com a concentração total de alquil-alumínio na reação $(\mathrm{mmol} / 100 \mathrm{~g} \mathrm{Bd})$, ao invés da razão molar $\mathrm{Al} / \mathrm{Nd}$, Figura 8. Dessa forma, o "delta” de viscosidade Mooney, representado pela distância observada entre as três diferentes reta, originada dos pontos experimentais, é consequência, somente, da diferença entre os valores de concentração de neodímio utilizados e parece tender a um mesmo valor para altas concentrações de alquilalumínio.

A viscosidade Mooney é uma variável de controle em processos industriais. Valores abaixo de 35 a $40 \mathrm{ou}$ acima de 70 a $75 \mathrm{ML}_{4}$, não são considerados normais para polímeros comerciais. E, quanto maior for a flexibilidade do sistema em relação ao controle da massa molar, consequentemente, da viscosidade Mooney, mais robusto e versátil torna-se o processo. A partir da Figura 8, ou um detalhamento maior da mesma, é possível escolher qual a melhor combinação [Nd] x [Al], para a produção do polímero comercialmente desejado.

\section{Conclusões}

A variação da concentração do composto clorado, na composição do sistema catalítico (razão molar $\mathrm{Cl} / \mathrm{Nd}$ ), afetou significativamente a atividade do catalisador, a massa molar, a distribuição da massa molar e a viscosidade Mooney do polímero, enquanto a microestrutura foi só ligeiramente modificada. Foi verificado uma razão molar $\mathrm{Cl} / \mathrm{Nd}$ maior ou igual a 3, para se obter um teor de cis máximo e entre 3 e 5, para atividade catalítica máxima. Os dados de conversão versus tempo de reação, para cada razão molar Al/Nd estudada, mostraram que a velocidade de polimerização aumenta com a razão molar $\mathrm{Al} / \mathrm{Nd}$, passa por um máximo, em $\mathrm{Al} / \mathrm{Nd}=23$, e decresce ligeiramente com aumentos adicionais desta razão. A microestrutura do polibutadieno foi significativamente influenciada pelo aumento da razão molar $\mathrm{Al} / \mathrm{Nd}$, passando de um valor próximo a $99 \%$ de unidades 1,4-cis, em razão mol ar $\mathrm{Al} / \mathrm{Nd}=10$, para um valor próximo a $93 \%$ de unidades 1,4-cis, para razão molar $\mathrm{Al} / \mathrm{Nd}=50$. As curvas de distribuição de massa molar evidenciam, também, um significativo processo de transferência de cadeia para os polímeros produzidos em razões $\mathrm{Al} / \mathrm{Nd}$ mais altas. 


\section{Agradecimentos}

Os autores agradecem a Petroflex Indústria e Comércio S.A. (atualmente Lanxess) pelo suporte financeiro a este trabalho.

\section{Referências Bibliográficas}

1. Pires, N. M. T. - "Estudo de sistemas catalíticos à base de neodímio para a produção de polibutadieno alto-cis", Tese de Doutorado, Universidade Federal do Rio de Janeiro, Brasil (2004).

2. Zhang, Z.; Cui, D.; Wang, B.; Liu, B. \& Yang, Y. - Struct. Bond., 137, p.49 (2010). http://dx.doi. org/10.1007/430_2010_16

3. Pires, N. M. T.; Ferreira, A. A.; Lira, C. H.; Coutinho, P. A.; Nicolini, L. F.; Soares, B. G. \& Coutinho, F. M. B. - J. Appl. Polym. Sci., 99, p.88 (2006). http://dx.doi.org/10.1002/ app. 22386

4. Mello, I. L.; Soares, B. G.; Coutinho, F. M. B. \& Nunes, D. S. S. - Polímeros, 14, p.235 (2004). http://dx.doi. org/10.1590/S0104-14282004000400008

5. Pires, N. M. T.; Coutinho, F. M. B.; Costa, M. A. S.; SantaMaria, L. C.; Mello, I. L. \& Nunes, D. S. S. - Rev. Quím. Ind., 719, p.15 (2002).

6. Fries, H. - "Structure and properties of butadiene rubber", in: Proceedings of 134th Meeting of The Rubber Division, Cincinnati, 1988. Washington: ACS, 1988. paper n. 8.

7. Hsieh, H. L. \& Yeh, H. C. - Rubber Chem. Technol., 58, p.117 (1985). http://dx.doi.org/10.5254/1.3536054

8. Dolgoplosk, B. A. \& Tinyakova, E. I. - Polym. Sci. Ser. A, 36, p.1380 (1994).

9. Quirk, R. P.; Kells, A. M.; Yunlu, K. \& Cuif, J. P. - Polymer, 41, p.5903 (2000). http://dx.doi.org/10.1016/ S0032-3861(99)00775-2

10. Ferreira, C. N.; Mello, I. L. \& Coutinho, F. B. - Polímeros, 19, p.138 (2009). http://dx.doi.org/10.1590/ S0104-14282009000200011

11. Proß, A.; Marquardt, P.; Reichert, K. H.; Nentwig, W. \& Knauf, T. - Angew. Makromol. Chem., 211, p.89 (1993). http://dx.doi.org/10.1002/apmc.1993.052110108

12. Gehrke, K.; Boldt, D.; Gebauer, U. \& Lechner, M. D. - Kaut. Gummi Kunstst., 49, p.510 (1996).

13. Wilson, D. J. \& Jenkins, D. K. - Polym. Bull., 34, p. 257 (1995). http://dx.doi.org/10.1007/BF00294142

14. Quirk,R.P.\& Kells,A.M.-Polym.Int.,49,p.751(2000).http:// dx.doi.org/10.1002/1097-0126(200007)49:7<751::AIDPI449>3.0.CO;2-K

15. Oehme, A.; Gebauer, U.; Gehrke, K.; Beyer, P.; Hartmann, B. \& Lechner, M. D. - Macromol. Chem. Phys., 195, p.3773 (1994). http://dx.doi.org/10.1002/macp.1994.021951203

16. Monakov, Yu. B.; Marina, N. G. \& Tolstikov, G. A. - Polim Med., 34, p.263 (1989).

17. Cabassi, F.; Italia, S.; Ricci, G. \& Porri, L. - "Neodymium catalysts for 1,3-diene polymerization. Some observations on their activity and stereospecificity", in: Transition Metal Catalyzed Polymerizations Ziegler-Natta and Metathesis Polymerizations, p.655, R. P. Quirk (ed.), Cambridge University Press, Cambridge (1988).
18. Ricci, G.; Italia, S.; Cabassi, F. \& Porri, L. - Polym. Comunn., 28, p.223 (1987).

19. Zavadovskaya, E. N.; Yakolev, V. A.; Tinyakova, E. I. \& Dolgoplosk, B. A. - Polym. Sci. USSR, 34, p.223 (1992).

20. Fraga, L. A.; Tavares, M. I. B.; Coutinho, F. M. B.; Costa, M. A. S. \& Santa-Maria, L. C. - Polímeros, 13, p.229 (2003). http://dx.doi.org/10.1590/S0104-14282003000400007

21. Nickaf, J. B.; Burford, R. P. \& Chaplin, R. P. - J Polym Sci A Polym Chem., 33, p.1125 (1995). http://dx.doi. org/10.1002/pola.1995.080330715

22. Oehme, A.; Gebauer, U. \& Gehrke, K. - J. Mol. Catal., 82, p.83 (1993). http://dx.doi.org/10.1016/03045102(93)80073-4

23. Monakov, Yu.B.; Marina, N. G. \& Sabirov, Z. M. - Polym Sci Ser A Chem Phys, 36, p.1404 (1994).

24. Xianzhong, J.; Shufen, P.; Yuliang, L. \& Jun, O. - Sci. Sin. B Chem. Biol. Agr. Med. Earth Sci., XXIV, p.8 (1986).

25. Hsieh, H. L. \& Yeh, G. H. C. - Ind. Eng. Chem. Res., 25, p.456 (1986). http://dx.doi.org/10.1021/i300023a016

26. Zhiquan, S.; Jun, O.; Fusong, W; Zhenya, H.; Fusheng, Y. \& Baogong, Q. - Polym Sci Ser A Chem Phys, 18, p.3345 (1980).

27. Porri, L. \& Giarrusso, A. - "Conjugated Diene Polymerization" in: Eastmond, G. C. et al. Comprehensive Polymer Science: the synthesis, characterization, reactions and applications of polymers, v.4, p.53, Geoffrey Eastmond, Anthony Ledwith, Saverio Russo, Pierre Sigwalt (ed.), Pergamon Press, New York, (1989).

28. Porri, L.; Ricci, G. \& Shubin, N. - Olefin Polymerization, 749, p.15 (2000). http://dx.doi.org/10.1021/bk-2000-0749.ch002

29. Porri, L.; Giarrusso, A. \& Ricci, G. - Makromol. Chem. Macromol. Symp., 66, p.231 (1993).

30. Murinov, Yu.I. \& Monakov, Yu. B. - Inorganica Chim Acta, 140, p.25 (1987). http://dx.doi.org/10.1016/S00201693(00)81040-3

31. Skuratov, K. D.; Lobach, M. I.; Shibaeva, A. N.; Churlyaeva, L. A.; Erokhina, T. V.; Osetrova, L. V. \& Kormer, V. A. - Polymer, 33, p.5197 (1992). http://dx.doi. org/10.1016/0032-3861(92)90801-3

32. Bodrova, V. S.; Piskareva, Ye.P.; Bubnova, S. V. \& Kormer, V. A. - Vysokomol. Soedinen. A, 30, p.2301 (1988).

33. Schröder, E.; Müller, G. \& Arndt, K. F. - "Polymer Characterization", Hanser Publishers, Munich (1989).

34. Kwag, G. "New ultra high cis polybutadiene technology through a novel neodymium catalyst and its vulcanizate properties", in: Proceedings of Symposium of International Rubber Conference, p. 174, Beijing, China (2004).

35. Wilson, D. J. - Makromol. Chem. Macromol. Symp., 66, p.273 (1993)

36. Wilson, D. J. \& Jenkins, D. K. - Polym. Bull., 27, p.407 (1992). http://dx.doi.org/10.1007/BF00309697

37. Monakov, Yu. B.; Marina, N. G. \& Sabirov, Z. M. - Polym Sci Ser A Chem Phys, 36, p.309 (1994).

38. Mazzei, A. - Macromol Chem Phys, 4, p.61 (1981). http:// dx.doi.org/10.1002/macp.1981.020041981105

Enviado: 09/03/13

Reenviado: $28 / 07 / 13$

Aceito: 09/09/13 